\title{
Mechanistic and Functional Divergence Between Thyrotropin- releasing Hormone and RO 15-4513 Interactions with Ethanol
}

\author{
Thomas J. McCown and George R. Breese \\ From the Departments of Psychiatry, Pharmacology, and the Biological Sciences Research Center, \\ University of North Carolina at Chapel Hill, Chapel Hill, North Carolina.
}

\section{Abstract}

Both thyrotropin-releasing hormone (TRH) and RO 15-4513 antagonize ethanol-induced depression, but this common property does not infer that both compounds share similar mechanisms of action. In the present studies, both TRH (30 mg/kg, i.p.) and RO $15-4513$ (10 mg/kg, i.p.) reversed ethanolinduced depression of locomotor activity, in accord with previous reports. However, the benzodiazepine antagonist, RO 15-1788, blocked this action of RO 15-4513, while exerting no effect on the analeptic action of TRH. Using a model of seizure activity electrically elicited from the inferior colliculus, ethanol exerted a dose-related attenuation of seizure activity. This anticonvulsant action of ethanol was not altered by TRH (30 mg/kg, i.p.), but RO $15-4513(3 \mathrm{mg} / \mathrm{kg})$ reversed the effect of the 0.5 , but not the $1.0 \mathrm{~g} / \mathrm{kg}$, dose of ethanol. In addition, pretreatment with RO 15-4513 (1 or 3 $\mathrm{mg} / \mathrm{kg}$, i.p.), but not TRH ( $30 \mathrm{mg} / \mathrm{kg}$, i.p.), caused seizure generalization into the forebrain following inferior collicular stimulation, further verifying the proconvulsant properties of RO 15-4513. In conclusion, the analeptic action of TRH appears independent of benzodiazepine activity, and in contrast to RO 15-4513, TRH does not exhibit proconvulsant properties. Furthermore, because TRH did not antagonize both depressant actions of ethanol studied, it appears unlikely that TRH directly interacts with the molecular basis of ethanol action.

Several chemically dissimilar compounds have been found to antagonize the sedative actions of ethanol, such as bicuculline, picrotoxin, pentylenetetrazol and most recently RO $15-4513.1^{-3}$ A property common to most of these compounds is the ability to influence the function of the $\gamma$-aminobutyric acid-benzodiazepine-chloride channel complex. ${ }^{4}$ Another compound that can reverse the depressant actions of ethanol is thyrotropin-releasing hormone (TRH) ${ }^{5-} 8$ Although several investigators have reported that benzodiazepines displace in vitro TRH binding, 9,10 the biological relationship of this interaction to the analeptic action of TRH has not been delineated.

Another commonality among many ethanol antagonists is their proconvulsant property. Similarly, withdrawal from chronic ethanol treatment induces a proconvulsant state, where audiogenic seizures can be elicited. These audiogenic seizures depend upon function within the inferior colliculus. ${ }^{11}$ An identical convulsive progression can be elicited by chronic electrical stimulation of the inferior collicular cortex, ${ }^{12}$ and this inferior colliculus stimulation model allows quantification of both anti- and proconvulsant activity. However, there have been no reports of a proconvulsant action of TRH.

Copyright $(\subset 1989$ by The Research Society on Alcoholism.

Reprint requests: Dr. Thomas J. McCown, 223 Biological Sciences Research Center, Campus Box 7250, University of North Carolina, Chapel Hill, NC 27599-7250. 
In the present investigations, we have utilized ethanol-induced depression of locomotor activity and an ethanol sensitive seizure model to evaluate TRH and RO 15-4513 interactions with ethanol. By combining the locomotor and seizure measures of ethanol action, both functional and mechanistic properties of TRH and RO 15-4513 could be compared.

\section{MATERIALS AND METHODS}

Animals

All of the animals were viral-free, male Sprague-Dawley rats weighing between 350 and 400 g. The animals were maintained under a 12-hr light-dark cycle (7:00 a.m. to 7:00 p.m. light) and provided free access to water and food.

\section{Locomotor Activity Measures}

Locomotor activity was quantified using eight doughnut-shaped activity monitors housed in sound-attenuated, fan-ventilated chambers each illuminated with a 7 -w lamp. ${ }^{13}$ Six photocells were evenly spaced about a circular runway $(9 \mathrm{~cm}$ inside; $30 \mathrm{~cm}$ outside diameter, $20 \mathrm{~cm}$ deep); each interruption of the photocell beam was recorded as an activity count. Counts were accumulated every 10 min over a 1.5 -hr period.

\section{Electrode Implantation and Seizure Testing}

The animals were anesthetized with $40 \mathrm{mg} / \mathrm{kg}$ pentobarbital and placed into a stereotaxic frame. Then, a bipolar electrode (insulated 0.008-inch stainless steel wire) was implanted into the inferior collicular cortex $(0.28 \mathrm{~mm} \mathrm{IAL}, 1.7 \mathrm{~mm} \mathrm{~L}, 3.6 \mathrm{~mm} \mathrm{~V})$ according to the atlas of Paxinos and Watson. ${ }^{14}$ The implant was secured with cranioplastic cement to four screws placed in the skull, and the animals were allowed at least 7 days to recover from the surgery.

After the recovery period, the animals received electrical stimulation of the inferior collicular cortex $(30 \mathrm{~Hz}, 1.5 \mathrm{msec}$ duration, monophasic square waves) using a current titration method as previously described. ${ }^{12}$ This allowed determination of the minimum current intensity necessary to produce poststimulus wild running and measurement of the wild running duration for each animal. A stable threshold current for seizure initiation then was determined over three to four trials. Subsequently, if the animals were stimulated twice a day, the wild running duration increased until on a given test, the wild running seizure was followed by the appearance of forelimb tonic extension and hindlimb clonus, indicants that seizure activity had generalized from the inferior collicular cortex into the forebrain.12 This seizure generalization demarcates an increase in seizure severity. Thus, prior to electrically induced seizure spread, the appearance of generalized seizure behaviors after a drug treatment establishes a proconvulsant action for the drug. Anticonvulsant effects can be measured at any point in the testing procedure, using changes in seizure threshold current or attenuation of seizure generalization.

\section{Drug Testing}

For the locomotor studies, all animals were treated first with $2.0 \mathrm{~g} / \mathrm{kg}$ ethanol i.p. and $1 \mathrm{~min}$ later received either TRH (30 mg/kg, i.p.) or RO $15-4513$ (10 mg/kg, i.p.). Previous investigations have shown that these doses of TRH or RO 15-4513 effectively reverse ethanolinduced sedation. ${ }^{2}, 5$ In studies using RO 15-1788, this compound was administered 1-min postethanol, while the TRH or RO 15-4513 was administered 2-min postethanol. Control groups included saline, TRH, or RO 15-4513 alone.

In order to evaluate the anticonvulsant activity of ethanol in the inferior collicular seizure model, the effects of various doses of ethanol $(0.3,0.5$, and $1.0 \mathrm{~g} / \mathrm{kg}$, i.p.) were assessed 30 min after ethanol administration. The interaction between ethanol and RO 15-4513 was 
assessed by administering $3.0 \mathrm{mg} / \mathrm{kg}$ RO $15-45132 \mathrm{~min}$ prior to the administration of either 0.5 or $1.0 \mathrm{~g} / \mathrm{kg}$ dose of ethanol and assessing seizure activity $30 \mathrm{~min}$ later. The TRH-ethanol interaction involved initial treatment with $0.5 \mathrm{~g} / \mathrm{kg}$ ethanol, then $15 \mathrm{~min}$ later administration of $30 \mathrm{mg} / \mathrm{kg} \mathrm{TRH}$, and finally $15 \mathrm{~min}$ post-TRH, the seizure activity was assessed.

Proconvulsant properties of these ethanol antagonists were evaluated by administering doses of RO $15-4513$ (1.0 or $3.0 \mathrm{mg} / \mathrm{kg}$, i.p.) $30 \mathrm{~min}$ prior to the seizure threshold test, or a dose of TRH (30 mg/kg, i.p.) $15 \mathrm{~min}$ prior to the seizure threshold test.

\section{Statistics}

The effects of the various drug treatments in the locomotor activity tests were evaluated by a one-way analysis of variance, followed by $t$ tests for multiple comparisons. The incidence of seizure generalization was evaluated by a $\chi^{2}$ test, while the threshold current for seizure initiation was evaluated by a paired $t$ test for repeated measures. A probability of $p<0.05$ was considered a significant change.

\section{RESULTS}

\section{Effect of TRH and RO 15-4513 on Ethanol-induced Impairment of Locomotor Activity}

In agreement with previous investigations, ${ }^{6}$ ethanol significantly decreased locomotor activity and TRH reversed this depressant action of ethanol (Fig 1). Like TRH, RO 15-4513 reversed the ethanol-induced depression of locomotor activity. The time course for this antagonism of ethanol sedation, shown in Fig. 2, appears similar for both TRH and RO 15-4513. The benzodiazepine antagonist, RO 15-1788, blocked this analeptic action of RO 15-4513 (Fig. 1), in agreement with previous reports. ${ }^{2,} 3$ In contrast, RO 15-1788 did not alter the analeptic action of TRH. Fig. 1 shows that the combination of TRH and RO 15-1788 produced more activity than TRH alone, even though this change did not reach significance $(p<0.1)$. RO 15-1788 had no effect on ethanol-induced depression of locomotor by itself (ethanol alone $=$ $546 \pm 164$ counts $/ 90 \mathrm{~min}$; ethanol $+\mathrm{RO} 15-1788=627 \pm 78$ counts $/ 90 \mathrm{~min})$. When compared to saline controls (1388 \pm 490 counts $/ 90 \mathrm{~min})$, RO $15-4513(10 \mathrm{mg} / \mathrm{kg}$, i.p.) alone did not alter locomotor activity ( $1440 \pm 580$ counts $/ 90 \mathrm{~min})$, but TRH $(30 \mathrm{mg} / \mathrm{kg}$, i.p. $)$ alone did significantly elevate locomotor activity (3214 \pm 476 counts $/ 90 \mathrm{~min})$.

\section{Effect of Ethanol on Inferior Collicular Seizure Activity}

The initial assessment of ethanol action on inferior collicular seizure activity used chronically stimulated animals, such that indicants of seizure generalization (i.e., the appearance of forelimb tonus followed by hindlimb clonus) occurred following an acute inferior collicular stimulation. In these animals, the $0.3 \mathrm{~g} / \mathrm{kg}$ dose of ethanol had no effect on seizure spread from the inferior colliculus to the forebrain (Table 1), while the 0.5 and $1.0 \mathrm{~g} / \mathrm{kg}$ doses of ethanol completely blocked the appearance of forelimb tonus and hindlimb clonus. In addition, Table 1 shows that the 0.3 and $0.5 \mathrm{~g} / \mathrm{kg}$ dose of ethanol had no effect on the threshold current for seizure initiation, but the $1.0 \mathrm{~g} / \mathrm{kg}$ dose produced a small, but significant, elevation in the seizure threshold current.

\section{Effects of TRH and RO 15-4513 on the Anticonvulsant Action of Ethanol}

As seen in Table 2, the attenuation of seizure generalization caused by $0.5 \mathrm{mg} / \mathrm{kg}$ ethanol was completely prevented by $3.0 \mathrm{mg} / \mathrm{kg}$ of RO 15-4513. However, this dose of RO 15-4513 had no effect on attenuation of seizure generalization induced by the $1.0 \mathrm{~g} / \mathrm{kg}$ dose of ethanol. Conversely, TRH $(30 \mathrm{mg} / \mathrm{kg})$ had no effect on the ethanol attenuation of seizure generalization. 


\section{Effects of RO 15-4513 and TRH on Seizure Generalization}

In acutely stimulated animals, seizure generalization does not appear after the wild running seizure. Pretreatment with various doses of RO 15-4513 caused an increasing incidence of seizure generalization without changing the threshold current for seizure initiation (Table 3). A high dose of TRH $(30 \mathrm{mg} / \mathrm{kg})$ had no effect on seizure generalization or on the threshold current for seizure initiation (Table 3).

\section{DISCUSSION}

The locomotor studies verified that both TRH and RO 15-4513 can reverse ethanol-induced sedation. As previously reported, ${ }^{2}$ the analeptic action of RO 15-4513 was shown to depend upon an interaction with the benzodizepine receptor. However, blockade of the benzodiazepine receptor by RO 15.1788 did not alter the analeptic action of TRH. Thus, the TRH reversal of ethanol-induced sedation does not depend upon a benzodiazepine receptor interaction- a finding which implies that the in vitro displacement of TRH binding by benzodiazepines ${ }^{9}, 10$ is not pertinent to the in vivo analeptic action of TRH.

Two other neurotransmitter systems, acetylcholine and $\gamma$-aminobutyric acid, have been implicated in the actions of TRH, ${ }^{15}, 16$ but no direct link has been established between functional measures of these neurotransmitter systems with the analeptic actions of TRH. ${ }^{6}$,

17 Therefore, unlike RO 15-4513, the neurochemical basis for the analeptic action of TRH remains to be defined. In this regard, both the present results and previous investigations 6,8 emphasize site specificity of TRH action within the brain. As a result of this site specificity, future mechanistic studies must focus on those brain areas pertinent to the particular functional consequence of TRH being studied.

Using a seizure model that resembles audiogenic ethanol withdrawal seizure activity, low doses of ethanol were found to exert anticonvulsant activity. The most prominent anticonvulsant property of ethanol was the attenuation of seizure spread from the brainstem area into the cortex, although the highest dose of ethanol $(1.0 \mathrm{~g} / \mathrm{kg})$ significantly elevated the threshold current for seizure initiation. This parallel to the report that ethanol administration attenuates audiogenic seizure activity in animals withdrawn from chronic ethanol treatment ${ }^{17}$ reinforces the probable interaction between ethanol and inferior collicular function. 18

When the interaction between RO 15-4513 and ethanol anticonvulsant action was tested, the results proved dependent upon the dose of ethanol. RO 15-4513 completely antagonized the anticonvulsant action of the $0.5 \mathrm{~g} / \mathrm{kg}$ dose of ethanol, but did not alter the anticonvulsant effects of the $1.0 \mathrm{~g} / \mathrm{kg}$ dose of ethanol. If administered alone, RO 15-4513 caused seizure generalization from the brainstem into the forebrain. An identical facilitation of seizure generalization also occurs following the administration of a subconvulsant dose of pentylenetetrazol. ${ }^{12}$ This similarity reinforces the conclusion that RO 15-4513 exhibits proconvulsant activity. ${ }^{20}$ Given the diametrically opposed action that each compound has upon inferior collicular seizure activity, one easily could describe this interaction as an ethanol antagonsim of the proconvulsant effects of RO 15-4513. As previously proposed by other investigators, $1,19,20$ this dose-dependent interaction is suggestive of a mutual antagonism. However, the present studies do not allow any conclusion regarding the molecular basis for the RO 15-4513-ethanol interaction.

In contrast to RO 15-4513, a TRH dose three times that needed to reverse ethanol sedation ${ }^{7}$ did not affect seizure sensitivity. Furthermore, TRH administration did not alter the anticonvulsant effects of ethanol. The dramatic TRH antagonism of high dose ethanol-induced sedation is the antithesis of the total lack of TRH action on low dose ethanol attenuation of seizure generalization. If TRH were directly interacting with the molecular basis of ethanol 
action on the brain, then TRH should exert some influence on both measures of ethanol action on the brain. Therefore, TRH must antagonize ethanol-induced sedation through a mechanism distinct from the molecular mechanism by which ethanol attenuates seizure activity.

In summary, the present findings reinforce previous conclusions that RO 15-4513 reverses ethanol-induced depression, exhibits proconvulsant properties, and appears to function through the $\gamma$-aminobutyric acid-benzodiazepine-chloride channel complex. ${ }^{1-3}$ In contrast to RO 15-4513, TRH neither exhibits proconvulsant properties, nor depends upon benzodiazepine receptor function, even though the analeptic properties are as marked as those for RO 15-4513. Clearly an analeptic mechanism exists in brain that is not linked to the benzodiazepine receptor, and is not proconvulsant in nature.

\section{Acknowledgments}

Supported by Grants HD-03110 and NS-26595.

\section{REFERENCES}

1. Lister RG, Nutt DJ. Is RO 15-4513 a specific alcohol antagonist? Trends Neurosci 1987;10:223-225.

2. Suzdak PD, Glowa JR, Crawley JN, Schartz RD, Skolnick P, Paul SM. A selective imidazobenzodiazepine antagonist of ethanol in the rat. Science 1986;234:1243-1247. [PubMed: 3022383]

3. Suzdak PD, Paul SM, Crawley NJ. Effects of RO 15-4513 and other benzodiazepine inverse agonists on alcohol-induced intoxication in the rat. J Pharmacol Exp Ther 1988;245:880-886. [PubMed: 2455039]

4. Olsen, RW.; Venter, JC., editors. Benzodiazepine/GABA receptors and chloride channels: structural and functional properties. New York: Alan R. Liss, Inc.; 1986.

5. Breese GR, Cott JM, Cooper BR, Prange AJ, Lipton MA. Antagonism of ethanol narcosis by thyrotropin-releasing hormone. Life Sci 1974;14:1053-1063. [PubMed: 4207201]

6. Breese GR, Frye GD, McCown TJ, Mueller RA. Comparison of the CNS effects induced by TRH and bicuculline after microinjection into medial septum, substantia nigra and inferior colliculus: absence of support for a GABA antagonist action for TRH. Pharmacol Biochem Behav 1984;21:145-149. [PubMed: 6431450]

7. Cott JM, Breese GR, Cooper BH, Barlow TS, Prange AJ. Investigations into the mechanism of reductions of ethanol sleep by thryrotropin-releasing hormone (TRH). J Pharmacol Exp Ther 1976;196:594-604. [PubMed: 177753]

8. McCown TJ, Moray LJ, Kizer JS, Breese GR. Interactions between TRH and ethanol in the medial septum. Pharmacol Biochem Behav 1986;24:1269-1274. [PubMed: 3088607]

9. Rinehart RK, Barbaz B, Iyengar S, Ambrose F, Steel DJ, Neale RF, Petrrack B, Bittiger H, Wood PL, Williams M. Benzodiazepine interactions with central thyroid-releasing hormone binding sites: characterization and physiological significance. J Pharmacol Exp Ther 1986;237:178-185. [PubMed: 3014114]

10. Sharif NA, Zuhowski EG, Burt G. Benzodiazepines compete for thyrotropin-releasing hormone receptor binding: micromolar potency in rat pituitary, retina and amygdala. Neurosci Lett 1983;41:301-306. [PubMed: 6320064]

11. Frye GD, McCown TJ, Breese GR. Characterization of susceptibility to audiogenic seizures in ethanol-dependent rats after microinjection of gamma-amminobutyric acid (GABA) agonists into the inferior colliculus, substantia nigra or medial septum. J Pharmacol Exp Ther 1093;227:663-670. [PubMed: 6317842]

12. McCown TJ, Greenwood RS, Frye GD, Breese GR. Electrically elicited seizure from the inferior colliculus: a potential site for the genesis of epilepsy? Exp Neurol 1984;86:526-534.

13. Hollister AS, Breese GR, Cooper BR. Comparison of tyrosine hydroxylase and dopamine- $\beta$ hydroxylase inhibition with the effects of 6-hydroxydopamine treatments on d-amphetamine induced motor activity. Psychopharmacology 1974;36:11-16. 
14. Paxinos, G.; Watson, C. The Rat Brain in Stereotaxic Coordinates. New York: Academic Press; 1986.

15. Cott J, Engel J. Antagonism of the analeptic activity of thyrotropin-releasing hormone (TRH) by agents which enhance GABA transmission. Psychopharmacology 1977;52:145-149. [PubMed: 18750]

16. Miyamoto M, Nagai Y, Narumi S, Saji Y, Nagawa Y. TRH and its novel analog (DN-1417): antipentobarbital action and involvement of cholinergic mechanisms. Pharmacol Biochem Behav 1982;17:797-806. [PubMed: 6817348]

17. Frye GD, Chapin RE, Vogel RA, Mailman RB, Kilts CD, Mueller RA, Breese GR. Effects of acute and chronic 1,3-butanediol treatment on central nervous system function: a comparison with ethanol. J Pharmacol Exp Ther 1981;216:306-314. [PubMed: 7193248]

18. Breese, GR.; Givens, BS.; McCown, TJ.; Criswell, HE. Strategy for investigating functions altered by ethanol at specific sites in brain: evidence that ethanol influences GAGA-benzodiazepine receptor complex function; Proceedings of the Fourth Congress of the International Society for Biomedical Research on Alcoholism; New York: Excerpta Medica; 1988.

19. Nutt DJ, Lister RG. The effect of the imidazodiazepine RO 15-4513 on the anticonvulsant effects of diazepam, sodium pentobarbital and ethanol. Brain Res 1987;413:193-196. [PubMed: 3036316]

20. Misslin R, Belzung C, Vogel E. Interaction of RO 15-4513 and ethanol on the behavior of mice: antagonistic or additive effects? Psychopharmacology 1988;94:392-396. [PubMed: 3128816] 


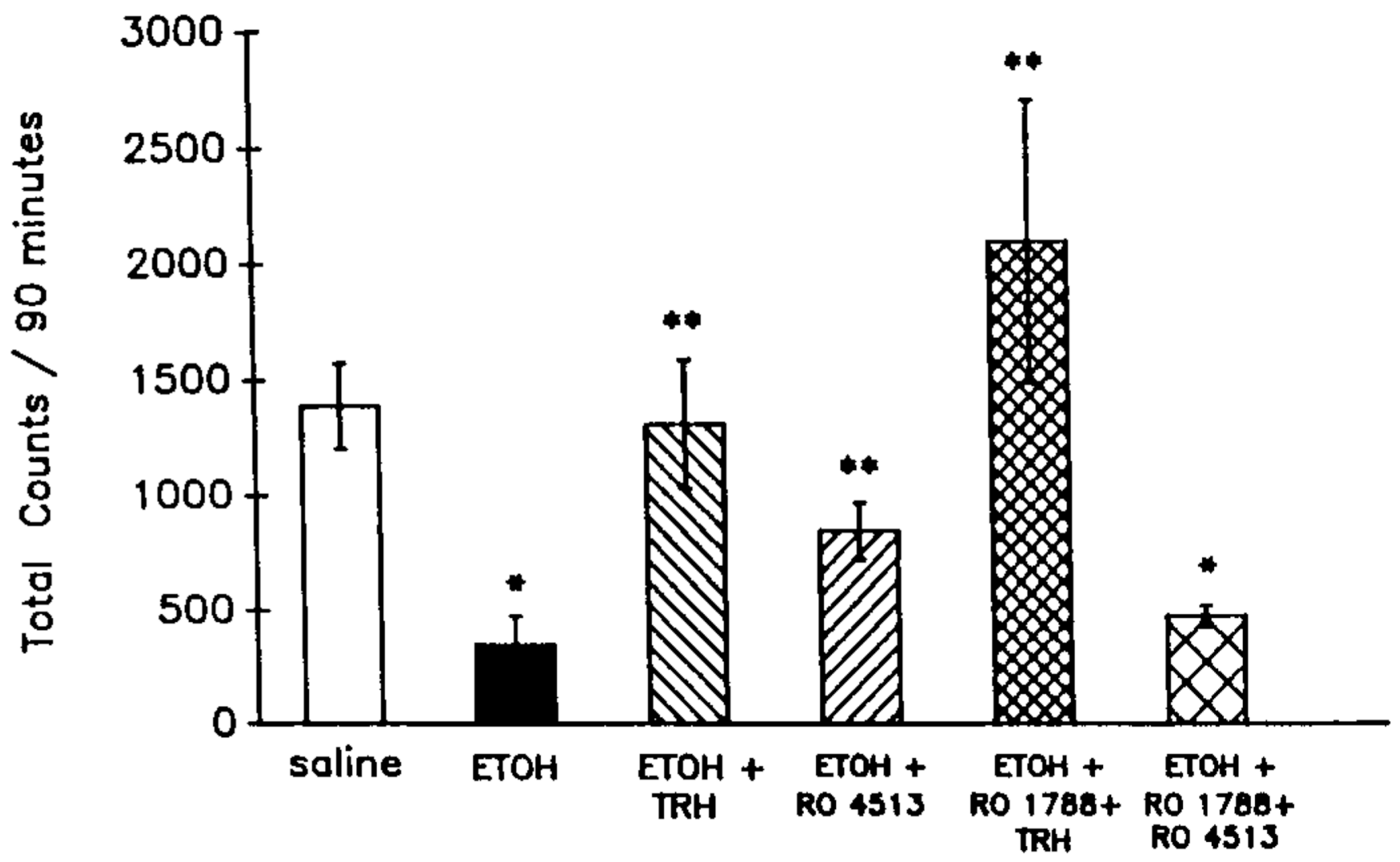

Fig. 1.

Effects of TRH and RO 15-4513 alone and in combination with RO 15-1788 on the depression of locomotor activity $( \pm$ SEM) induced by a $2.0 \mathrm{~g} / \mathrm{kg}$ i.p. dose of ethanol (ETOH). All animals were treated with ETOH and $1 \mathrm{~min}$ later received either TRH (30 mg/kg, i.p.), or RO 15-4513 (10 mg/kg, i.p). For RO 15-1788 studies, $10 \mathrm{mg} / \mathrm{kg}$ of this compound was administered, i.p., 1-min post-ETOH, while the TRH or RO 15-4513 was administered 2-min post-ETOH. * $p<$ 0.05 versus saline control; $* * p<0.05$ versus $\mathrm{ETOH}$ control. 


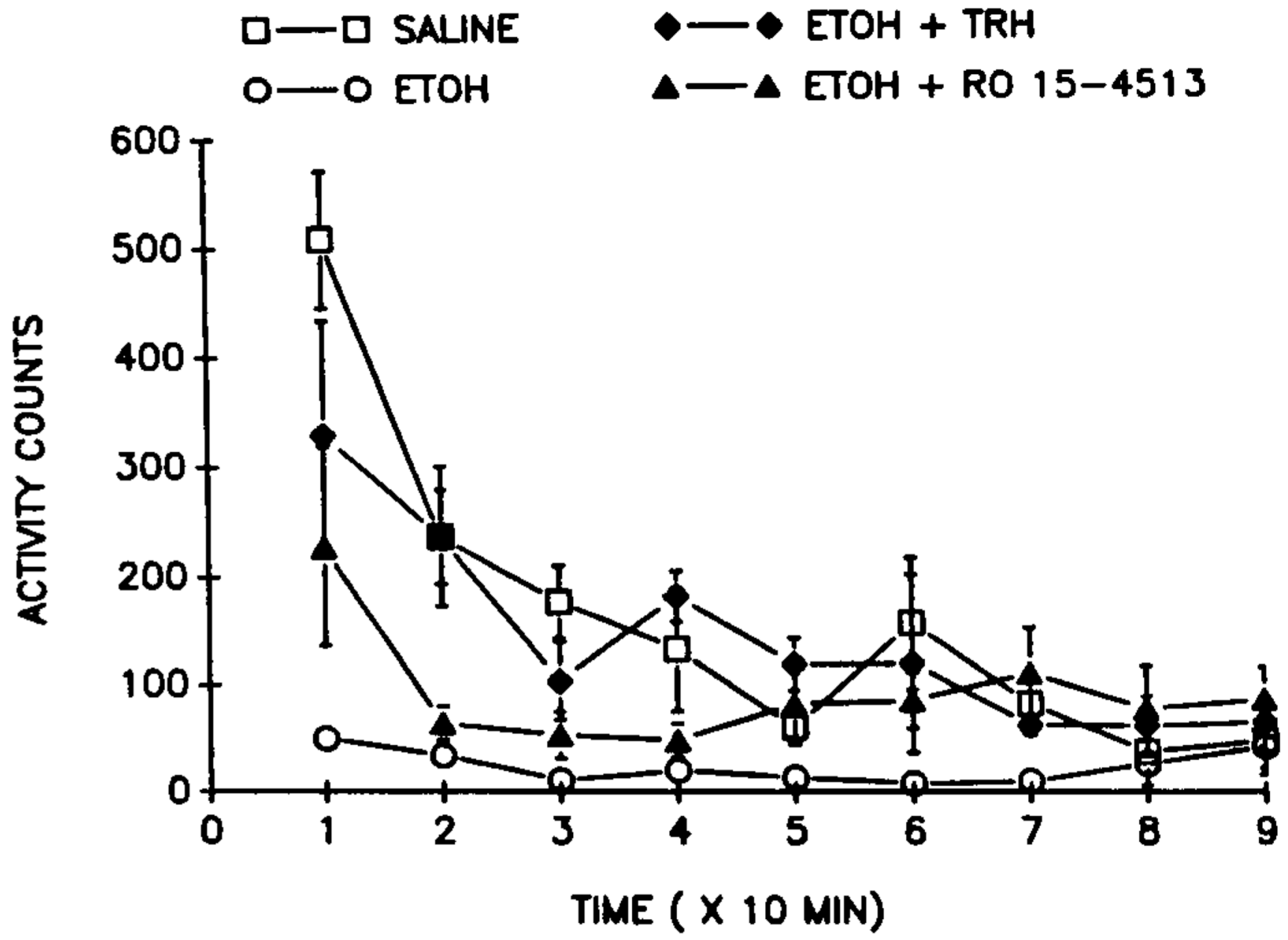

Fig. 2.

The time course of both the TRH and RO 15-4513 antagonism of ethanol sedation depicted in Fig. 1, as compared to ETOH or saline alone. The activity counts $( \pm$ SEM) were measured within each 10-min interval. 
Table 1

Effects of Ethanol on Inferior Collicular Seizure Activity

\begin{tabular}{lcl}
\hline ETOH dose & $\begin{array}{c}\text { Change in threshold } \\
\text { current }(\boldsymbol{\mu A})\end{array}$ & $\begin{array}{l}\text { Incidence of } \\
\text { seizure generalization }\end{array}$ \\
\hline Saline & $0 \pm 3$ & $7 / 7$ \\
$0.3 \mathrm{~g} / \mathrm{kg}$ & $0 \pm 0$ & $6 / 6$ \\
$0.5 \mathrm{~g} / \mathrm{kg}$ & $-4 \pm 2$ & $0 / 7^{\dagger}$ \\
$1.0 \mathrm{~g} / \mathrm{kg}$ & $31 \pm 14^{*}$ & $0 / 6^{\ddagger}$ \\
\hline
\end{tabular}

Ethanol was administered i.p. 30 min prior to the test for seizure activity.

${ }^{\dagger}$ All animals had received chronic stimulation of the inferior collicular cortex such that a given stimulation resulted in the appearance of forelimb tonic extension followed by hindlimb clonus, indicants of seizure generalization from the brainstem into the forebrain. The results are expressed as number exhibiting seizure generalization/total tested.

${ }^{*} p<0.05$, versus saline controls. 
Table 2

Effect of TRH or RO 15-4513 on Anticonvulsant Action of Ethanol

\begin{tabular}{ll}
\hline Treatment $^{*}$ & $\begin{array}{l}\text { Incidence of seizure } \\
\text { generalization }\end{array}$ \\
\hline $\begin{array}{l}\text { ETOH }(0.5 \mathrm{~g} / \mathrm{kg})+\mathrm{RO} 15-4513 \\
(3 \mathrm{mg} / \mathrm{kg})\end{array}$ & $5 / 5^{\dagger}$ \\
$\begin{array}{l}\mathrm{ETOH}(1 \mathrm{~g} / \mathrm{kg})+\mathrm{RO} 15-4513(3 \\
\mathrm{mg} / \mathrm{kg})\end{array}$ & $0 / 6$ \\
$\begin{array}{l}\mathrm{ETOH}(0.5 \mathrm{~g} / \mathrm{kg})+\mathrm{TRH}(30 \mathrm{mg} / \\
\mathrm{kg})\end{array}$ & $0 / 5$ \\
\hline
\end{tabular}

* RO 15-4513 was administered to animals 2 min prior to ethanol administration, and TRH was administered 15 min after the ethanol. All animals were tested $30 \mathrm{~min}$ after the ethanol administration.

${ }^{\dagger}$ All animals received chronic stimulation of the inferior collicular cortex such that a given stimulation resulted in the appearance of forelimb tonic extension followed by hindlimb clonus, indicants of seizure generalization from the brainstem into the forebrain. Results are expressed as number exhibiting seizure generalization/total tested.

$\#_{p}<0.05$, compared to the appropriate ETOH control. 
Table 3

Effect of TRH or RO 15-4513 on Seizure Generalization from the Inferior Colliculus Into the Forebrain

\begin{tabular}{ll}
\hline Treatment $^{*}$ & $\begin{array}{l}\text { Incidence of seizure } \\
\text { generalization }\end{array}$ \\
\hline Saline & $0 / 6$ \\
TRH $(30 \mathrm{mg} / \mathrm{kg})$ & $0 / 5$ \\
RO $15-4513$ & \\
$1.0 \mathrm{mg} / \mathrm{kg}$ & $3 / 5^{+}$ \\
$3.0 \mathrm{mg} / \mathrm{kg}$ & $5 / 5^{\dagger}$ \\
\hline
\end{tabular}

TRH was administered to animals 15 min prior to seizure testing, while RO 15-4513 was administered 30 min prior to seizure testing.

${ }^{\dagger}$ The animals had not received chronic stimulation of the inferior collicular cortex, so upon a given stimulation no seizure generalization would be expected. Results are expressed as number exhibiting seizure generalization/total tested. No treatment altered the seizure threshold current.

${ }^{\ddagger} p<0.05$, compared to saline control. 